\title{
Reproductive isolation of a new hybrid species, Senecio eboracensis Abbott \& Lowe (Asteraceae)
}

\author{
AJ Lowe ${ }^{1,2,3}$ and RJ Abbott ${ }^{1}$ \\ ${ }^{1}$ Division of Environmental and Evolutionary Biology, School of Biology, Mitchell Building, University of St Andrews, Fife, KY16 9TH, \\ UK; ${ }^{2}$ School of Life Sciences, University of Queensland, Brisbane QLD 4072, Australia
}

\begin{abstract}
The nature and extent of reproductive isolation was examined between a new self-compatible hybrid species Senecio eboracensis $(2 n=40)$ and its parents, self-incompatible $S$. squalidus $(2 n=20)$ and self-compatible $S$. vulgaris $(2 n=40)$. The triploid $F_{1}$ of $S$. eboracensis $\times S$. squalidus exhibited very low seed set $(\bar{x}=0.63 \%)$, and $F_{2}$ and $F_{3}$ progeny were able to recover nominal levels of fertility $(\bar{x}=23.9$ and $9.7 \%)$, while $\mathrm{F}_{1}$ and $\mathrm{F}_{2}$ offspring of $S$. eboracensis $\times S$. vulgaris showed reduced seed set $(\bar{x}=63.8$ and $58.8 \%)$. In both cases, evidence from previous work indicates that reduced fertility is associated with meiotic chromosome mispairing, and is a likely consequence of recombining both parental genomes within this new taxon. No hybrid offspring between $S$. eboracensis and $S$. squalidus were found in the wild, and only one such hybrid was recorded among 769 progeny produced by $S$. eboracensis
\end{abstract}

surrounded by $S$. squalidus on an experimental plot. Natural crossing between $S$. eboracensis and $S$. vulgaris was recorded to be very low (between 0 and $1.46 \%$ ) in the wild, but rose to $18.3 \%$ when individuals of $S$. eboracensis were surrounded by plants of $S$. vulgaris. It was concluded that strong breeding barriers exist between the new hybrid species and its two parents. Prezygotic isolation between $S$. eboracensis and $S$. vulgaris is likely to be largely due to both species reproducing by predominant self-fertilisation. However, differences recorded for germination, seedling survival, time of flowering and characters associated with pollinator attraction, plus significant clumping of juvenile and adult conspecifics in the wild, probably also contribute to reproductive isolation and ecological differentiation.

Heredity (2004) 92, 386-395, advance online publication, 10 March 2004; doi:10.1038/sj.hdy.6800432

Keywords: hybridisation; polyploidy; reproductive isolation; Senecio; speciation

\section{Introduction}

Two major mechanisms responsible for the origin of new hybrid taxa are allopolyploidy (Winge, 1917) and recombination (Grant, 1981). Numerous studies examining the role of each of these mechanisms in the generation of hybrid species have been reported (Abbott, 1992; Soltis and Soltis, 1993, 1999; Arnold, 1997; Rieseberg, 1997; Rieseberg and Carney, 1998). Generally, polyploid hybrid lineages are isolated from parental taxa by a postzygotic isolating mechanism caused by chromosome mispairing in backcross offspring. Similarly, strong postzygotic reproductive isolating barriers often exist between homoploid recombinant hybrid species and their parents due to meiotic irregularities or the expression of sterility factors (Rieseberg et al, 1995; Rieseberg et al, 1996; Wolfe et al, 1998a). Less well known is the nature and extent of prezygotic reproductive isolation between a hybrid species and its parents, even though such isolation is crucial to the successful establishment of a new hybrid species.

Following its origin, a polyploid or homoploid hybrid neospecies will usually occur at low frequency in

Correspondence: AJ Lowe, Division of Environmental and Evolutionary Biology, School of Biology, Mitchell Building, University of St Andrews, Fife, KY16 9TH, UK.

${ }^{3}$ Current address: School of Life Sciences, University of Queensland, Brisbane QLD 4072, Australia. E-mail: a.lowe@uq.edu.au

Received 14 March 2003; accepted 8 January 2004; published online 10 March 2004 sympatry with its parents, and is likely to suffer a minority-type disadvantage if it reproduces by outcrossing (Levin, 1975). This is because most offspring will result from crosses with the parents and be sterile or exhibit low fertility (Felber, 1991; Husband, 2000). This disadvantage will be avoided if a prezygotic isolating mechanism prevents or reduces significantly the production of such offspring. Theoretical modelling shows that even relatively minor increases in autogamy, clumped distribution (McCarthy et al, 1995) or ecological differentiation (Buerkle et al, 2000) can favour the sympatric establishment of a new hybrid lineage. For example, in the outcrossing, homoploid hybrid species, Helianthus anomalus and $H$. paradoxus, prezygotic isolation is achieved from both parent taxa, $H$. annuus and $H$. petiolaris, by ecological separation (Schwarzbach et al, 2001; Welch and Rieseberg, 2002), which also helps to reduce the effects of competition with the parents. In the case of Penstemon clevelandii, the homoploid hybrid derivative of $P$. spectabilis and $P$. centranthifolius (Wolfe et al, 1998a, b), speciation was accompanied by a change of pollinator to carpenter bees, wasps and hummingbirds in the species complex (Straw, 1955, 1956). In the case of prezygotic isolation between polyploid and diploid cytotypes of the same species, field studies of Chamerion angustifolium have shown that the autotetraploid cytotype is prezygotically isolated from its diploid parent due to differences in flowering phenology, clumped distribution and pollinator selection (Husband and Schemske, 2000). 
In the British Isles, a novel hybrid species of the native tetraploid $S$. vulgaris $(2 n=40)$ and the introduced diploid $S$. squalidus $(2 n=20)$ was discovered by one of the authors (RJA) in 1979 in York, England. This species was originally referred to as 'York radiate groundsel', but has recently been formally described as S. eboracensis (Lowe and Abbott, 2003). It is tetraploid and possesses an intermediate morphological phenotype for capitulum and leaf characters (Irwin and Abbott, 1992; Lowe, 1996). Low levels of isozyme and cpDNA variation indicate that this hybrid species probably formed on only one occasion (Irwin and Abbott, 1992; Abbott and Lowe, 1996). However, crossing studies by Lowe and Abbott (2000) indicate that hybrid derivatives similar to $S$. eboracensis can be formed relatively easily, despite strong reproductive isolating mechanisms between their parent taxa, and thus a polytopic origin cannot be ruled out.

Studies of $S$. eboracensis from several sites around York over the last 20 years have shown that it has maintained its distinctive morphological and isozyme phenotype (Irwin and Abbott, 1992; Lowe, 1996), and appears, therefore, to be reproductively isolated from both parent taxa in the field (Abbott and Lowe, 1996). Here, we report an investigation into the nature and extent of reproductive isolation between this new hybrid species and its parents. First, we investigate postzygotic barriers by examining the fertility of first- and second-generation progeny of crosses and backcrosses between $S$. eboracensis and its parents. Second, we examine prezygotic isolation by estimating levels of hybrid formation in the field and on an experimental plot, as well as differences in germination under optimal conditions, and phenology and taxon distribution at a site in the wild. During the course of field studies, an opportunity arose to monitor the relative survival of seedlings produced by $S$. eboracensis and $S$. vulgaris at the same field site. The results of this particular investigation provided information on differences between these two species in winter survival and consequently a difference in their respective ecologies.

\section{Methods}

\section{Fertility of intertaxon crosses}

Reciprocal crosses were made between S. eboracensis and $S$. vulgaris var. vulgaris using the crossing method described by Lowe and Abbott (2000). Four $\mathrm{F}_{1}$ hybrids were raised to generate $F_{2}$ offspring (produced by selfing) and $B_{1}$ progeny. Thereafter, 204 plants, including 33 of $S$. vulgaris, 40 of $S$. eboracensis, $18 \mathrm{~F}_{1}$ hybrids, $72 \mathrm{~F}_{2}$ offspring and 41 reciprocal backcross offspring, were raised to maturity in a randomised block. In addition, reciprocal crosses were made between $S$. eboracensis and $S$. squalidus to generate six $F_{1}$ triploid hybrids, while another triploid hybrid was obtained naturally from a field experiment. From these triploid hybrids, nine $\mathrm{F}_{2}$ progeny were produced through open-pollination, while backcrossing to $S$. eboracensis formed five $\mathrm{B}_{1}$ progeny. A total of $10 \mathrm{~F}_{3}$ plants were produced from the $\mathrm{F}_{2} \mathrm{~S}$ following open-pollination, and backcrossing $F_{2}$ plants to $S$. eboracensis formed five backcross progeny $\left(B_{1.2}\right)$. Following this, $26 \mathrm{~B}_{1}$, nine $F_{2}$, five $B_{1}$, five $B_{1.2}$ and $10 F_{3}$ progeny were raised in a fully randomised design together with six individuals of $S$. squalidus and 11 of S. eboracensis. In both experiments, plants were grown in a glasshouse under the same conditions described in Lowe and Abbott (2000).

Two fertility characters were measured on each plant at maturity. Pollen fertility was estimated as the proportion of grains stained with acetocarmine from one floret of the second capitulum to open (flower) on each plant. Seed fertility was recorded as the proportion of seeds that matured in a randomly selected capitulum left to open-pollinate in a glasshouse. In addition, for $S$. eboracensis and $S$. vulgaris plants and offspring of crosses between them, one fitness character (life-time production of capitula) was measured. Measures of fitness and fertility were subjected to one-way ANOVA, and significant differences between taxa and generations were assessed by Tukey-Kramer multiple comparisons (SAS Institute, Inc., 1990).

\section{Phenology}

The total number of flowering individuals of $S$. vulgaris and $S$. eboracensis, growing in a car park at Dalton Terrace, York (OS105 593 512), were recorded on four different dates that spanned the flowering season in 1993 (6 May, 10 June, 30 June and 30 September). In 1994, the total number of flowering individuals and the total number of open capitula per plant were recorded at the same site for both taxa on six dates (23 March, 21 April, 18 May, 7 June, 14 July and 5 August). In both years no other Senecio taxa grew at the site.

\section{Germination}

Fresh seed (not more than 2-weeks old) of S. vulgaris var. vulgaris, S. eboracensis and S. squalidus originally collected from plants growing in York was germinated at five temperatures $\left(5,10,15,20\right.$ and $\left.25^{\circ} \mathrm{C}\right)$ over a period of 45 days. For each taxon, 20 seeds were placed together on $1 \mathrm{~cm}^{2}$ squares of moist $3 \mathrm{MM}$ blotting paper. The blotting paper squares were supported by plastic beads floating in the well of a thermogradient bar partly filled with water (Horrill, 1989). For each temperature treatment, three paper squares (one for each taxon) were located in a position along the thermogradient corresponding to the temperature treatment. The thermogradient bar contained 12 wells and thus each temperature/taxon treatment was replicated 12 times. Seeds were examined each day, and those that had germinated were removed. Results for analysis were expressed by day as the cumulative proportion of seeds germinated. Data were arcsine transformed before ANOVA.

\section{Seedling establishment}

On 22 September 1994, it was discovered that the Dalton Terrace site had been completely cleared of vegetation by persons unknown. This provided an opportunity to investigate subsequent seedling establishment and survival at the site. The distinctive leaf characteristics of S. eboracensis (Lowe and Abbott, 2003) are expressed at the first true leaf stage allowing seedlings of this species to be easily distinguished from those of $S$. vulgaris. It was therefore possible to classify seedlings according to species type. Eight, $1 \mathrm{~m}$ long linear transects were set out along the edge of the site and were surveyed on 26 November 1994, and on 16 February, 5 March and 25 July 1995. During the survey period, a record was taken of the number of individuals of each taxon present (established 
and new), the total number of leaves per plant (on 26 November, 16 February and 5 March only) and the number of flowering capitula per plant (on 5 March and 25 July only).

\section{Conspecific clustering}

To test whether S. vulgaris var. vulgaris and S. eboracensis displayed conspecific clumping at the Dalton Terrace field site, records documenting the spatial location of plants for adult populations during 1994 (14 S. eboracensis and $43 S$. vulgaris plants which grew along the edge of a wall, ie only a linear distance was recorded), and for seedling establishment along the eight, one metre long transects studied during 1994/95 (27 S. eboracensis and 92 S. vulgaris seedlings/plants, again a linear distance was used to position individuals) were analysed using spatial autocorrelation statistics (Degen et al, 2001). The observed Moran's Index ( $D$ (obs)) was calculated for each neighbourhood distance class using the software package SGS (by Bernd Degen, INRA Bordeaux). Positive and negative measures of the $95 \%$ confidence intervals $(D(+\mathrm{CI})$ and $D(-\mathrm{CI}))$ were produced based on 1000 resamplings of species types among the existing plant coordinate data. If $D$ (obs) is greater than the $D(+\mathrm{CI})$, then there is a significant autocorrelation at that distance class and therefore significant clustering of individuals by species type. Plots of Moran's Index against neighbourhood distance classes, called correlograms, were made to illustrate the level of conspecific clustering.

\section{Hybrid formation in the wild}

Up to 10 open-pollinated seeds were collected from plants of S. vulgaris var. vulgaris and S. eboracensis plants that were flowering at Dalton Terrace on three dates in 1993 (6 May, 10th and 30 June; a total of 966 seed from 120 S. eboracensis plants and 542 seed from 69 S. vulgaris plants), and on four dates in 1994 (21 April, 18 May, 7 June and 14 July; a total of 200 seed from 17 S. eboracensis plants and 797 seed from 57 S. vulgaris plants). Progeny were grown to maturity from these seeds and screened for hybrids between $S$. eboracensis and $S$. vulgaris. Hybrids were easily distinguished by the possession of short stubby ray florets and intermediate leaf morphology. Data from the 1993 samples were used to estimate the frequency of the radiate allele at the site, Wright's fixation index and the frequency of hybrid formation of S. vulgaris and S. eboracensis according to procedures described by Marshall and Abbott (1982).

\section{Hybrid formation under experimental conditions of open pollination}

A total of 140 individual plants of $S$. squalidus $(n=35)$, $S$. eboracensis $(n=70)$ and $S$. vulgaris var. vulgaris $(n=35)$ were raised under glass in $10 \mathrm{~cm}$ pots. Sowing was staggered to ensure that plants flowered synchronously. Shortly before flowering, plants were placed outside in the St Andrews Botanic Garden and assigned to four different types of unit within 12 different plots. Units varied in species composition and plant arrangement. In two units, a central plant of $S$. eboracensis was surrounded by four plants of either $S$. vulgaris or $S$. squalidus arranged in a square array with a distance of $15 \mathrm{~cm}$ between plants. In the other two units, a central plant of
S. squalidus or $S$. vulgaris was surrounded in similar fashion by four plants of $S$. eboracensis. The 12 different plots varied in the number and type of unit contained. Four plots, denoted as 'small size plots' were composed of a single unit, with a different unit represented in each plot. In another four plots, denoted as 'medium size plots', two units of the same type were placed side by side $15 \mathrm{~cm}$ apart, with each plot containing a different unit type. In the remaining four plots, denoted as 'large size plots', four units of the same type were arranged $15 \mathrm{~cm}$ apart in a square, with each plot containing a different unit type. The 12 plots were randomised within a $4 \times 3$ block with plots separated from each other by a distance of $20 \mathrm{~m}$.

Seed for progeny testing was sampled from central plants within units within plots on six different days (referred to as 'date' in the analysis). Plot positions within the block were rerandomised between sampling dates. Before sampling seed, one or more recently opened capitula were selected on central plant(s) within units. In single-unit plots, three capitula were selected on the central plant; in plots composed of two units, two capitula were selected on the central plant of one unit and a third capitulum was selected on the central plant of the other unit; in plots composed of four units; a single capitulum was selected on central plants in three of the units. Selected capitula were tagged and left to openpollinate over a 3-day period. Seed set in S. squalidus plants surrounded by $S$. eboracensis was very low and consequently the three plots containing these units were not analysed further. From the remaining nine plots, a sample of up to 20 seed was collected from each selected capitulum for progeny analysis. In total, 2209 seed from 162 capitula were sown out, and progeny were raised to flowering under glass to examine the frequency of hybrid progeny produced by central plants within units. Hybrid progeny were identified by morphology and confirmed by isozyme analysis (Lowe, 1996). Differences in frequency of hybrid formation were examined for unit type, plot size and sampling date using a three-way interaction of a General Linear Model (Minitab Inc., release 13.32, 2000).

\section{Results}

\section{Fertility of intertaxon crosses}

Pollen fertility in $F_{1}$ progeny of crosses between S. eboracensis and $S$. vulgaris was significantly lower than $S$. eboracensis but not $S$. vulgaris plants, whereas seed set in $\mathrm{F}_{1}$ progeny was significantly lower than $S$. vuglaris but not S. eboracensis plants (Table 1). Pollen fertility and seed set in $F_{2}$ progeny of crosses between $S$. eboracensis and S. vulgaris were significantly reduced relative to those of the parents (Table 1). Mean seed set in the $\mathrm{F}_{2}$ was $58.8 \%$ relative to $82.4 \%$ for $S$. vulgaris and $78.5 \%$ for $S$. eboracensis; however, some $F_{2}$ individuals set no seed, while others exhibited very high seed set (up to $89 \%$ ). Backcross progeny also exhibited a considerable range of seed set values, and the means although lower than those of the parents were not significantly different from those of $S$. eboracensis (Table 1). For pollen fertility, $\mathrm{F}_{2}$ progeny exhibited a significantly lower mean than $S$. vulgaris and S. eboracensis plants (Table 1 , range $62-100 \%$ ) as did $B_{1}$ progeny derived from backcrosses to $S$. vulgaris. How- 
Table 1 Means and standard deviations (in parentheses) of fertility and fitness traits measured on S. eboracensis, S. vulgaris var. vulgaris and S. squalidus, and offspring of intertaxon crosses and backcrosses

\begin{tabular}{|c|c|c|c|c|c|c|c|c|}
\hline $\begin{array}{l}\text { Taxa } \\
\text { Character }\end{array}$ & $\begin{array}{l}\text { S. vulgaris } \\
\text { var. vulgaris }\end{array}$ & S. eboracensis & $F_{1}$ & $F_{2}$ S. vulgaris & $\begin{array}{l}B_{1} \text { to } S . \\
\text { eboracensis }\end{array}$ & $\begin{array}{l}B_{1} \text { to var. } \\
\text { vulgaris }\end{array}$ & $\mathrm{P}$ & \\
\hline$N=$ & 33 & 40 & 18 & 72 & 21 & 20 & & \\
\hline Pollen fertility $\%$ & $97.6^{\mathrm{b}}(3.2)$ & $99.6^{\mathrm{a}}(0.5)$ & $97.0^{\mathrm{bc}}(3.4)$ & $94.5^{\mathrm{cd}}(7.5)$ & $92.1^{\mathrm{d}}(8.1)$ & $98.4^{\mathrm{ab}}(2.5)$ & $* * *$ & \\
\hline Seed set $\%$ & $82.4^{\mathrm{a}}(12.4)$ & $78.5^{\mathrm{ab}}(7.9)$ & $63.8^{\mathrm{bc}}(16.6)$ & $58.8^{c}(26.5)$ & $66.1^{\mathrm{abc}}(36.6)$ & $67.2^{\mathrm{bc}}(18.2)$ & $* * *$ & \\
\hline$N=$ & 19 & 11 & 10 & 40 & 18 & 10 & & \\
\hline $\begin{array}{l}\text { Total lifetime production } \\
\text { of capitula }\end{array}$ & $80.4(26.4)$ & $102.2(22.8)$ & $96.9(35.7)$ & $87.6(32.1)$ & $78.9(30.1)$ & $78.8(18.9)$ & ns & \\
\hline Taxa & S. squalidus & S. eboracensis & $F_{1}$ & $F_{2}$ & $\begin{array}{c}\mathrm{B}_{1} \text { to } \\
\text { S. eboracensis }\end{array}$ & $\mathrm{F}_{3}$ & $\begin{array}{l}\mathrm{B}_{1.2} \text { to } \\
\text { S. eboracensis }\end{array}$ & $\mathrm{P}$ \\
\hline \multicolumn{9}{|l|}{ Character } \\
\hline$N=$ & 6 & 11 & 7 & 9 & 26 & 10 & 5 & \\
\hline Pollen fertility $\%$ & $94.5^{\mathrm{a}}(9.6)$ & $77.5^{\mathrm{ab}}(21.2)$ & $36.6(10.2)^{c}$ & $69.5^{\mathrm{ab}}(35.6)$ & $65.5^{\mathrm{b}}(15.9)$ & $55.4^{\mathrm{bc}}(35.1)$ & $69.1^{\mathrm{b}}(9.2)$ & $* * *$ \\
\hline Seed set $\%$ & $72.3^{\mathrm{a}}(31.1)$ & $74.3^{\mathrm{a}}(24.9)$ & $0.63(10.8)^{c}$ & $23.9^{\mathrm{b}}(10.4)$ & $55.4^{\mathrm{a}}(35.1)$ & $9.7^{\mathrm{bc}}(18.2)$ & $13.3^{\mathrm{b}}(9.8)$ & $* * *$ \\
\hline
\end{tabular}

Significant differences $\left({ }^{* * *} P \leqslant 0.001,{ }^{* *} P \leqslant 0.01,{ }^{*} P \leqslant 0.05\right.$, ns $=$ not significant) and results of Tukey-Kramer multiple comparison are presented. Means sharing the same superscript are not significantly different $(P \leqslant 0.05)$.

ever, $B_{1}$ progeny derived from backcrosses to $S$. eboracensis showed a significant increase in mean pollen fertility relative to that of $\mathrm{F}_{2}$ progeny and this mean was not significantly different from those of the parents (Table 1). No significant difference in mean lifetime production of capitula was recorded between S. eboracensis and $S$. vulgaris or their $\mathrm{F}_{1}, \mathrm{~F}_{2}$ or $\mathrm{B}_{1}$ hybrid progeny.

Since $S$. squalidus is self-incompatible (Abbott and Forbes, 1993; Hiscock, 2000a, b), only open-pollinated seed was collected from parents and progeny of crosses with $S$. eboracensis. On average, triploid $F_{1}$ hybrids (verified by chromosome counts) were highly sterile and exhibited open seed set of $0.63 \%$ and pollen fertility of $36.6 \%$ (Table 1). However, fertility increased significantly in the $\mathrm{F}_{2}$ and $\mathrm{F}_{3}$ generations reaching 23.9 and $9.7 \%$, respectively, for seed set, and 69.5 and $55.4 \%$, respectively, for pollen fertility (Table 1). Fertility also increased by backcrossing $\mathrm{F}_{1}$ and $\mathrm{F}_{2}$ progeny to $S$. eboracensis, with mean pollen fertility reaching 65.5 and $69.1 \%$, respectively, and mean seed set 55.4 and $13.3 \%$, respectively.

\section{Field phenology, germination, seedling establishment and} conspecific clumping

Phenology: The number of plants flowering at Dalton Terrace on each sample date shows that S. eboracensis was later to flower than S. vulgaris in both 1993 and 1994 (Figure 1a and b). It was also evident that in 1994 there was a considerable difference between the two taxa in the time when the greatest number of capitula were open at the site (Figure 1c). In 1994, S. eboracensis individuals first flowered on average after 72.1 days (from the first day of the year), while $S$. vulgaris first flowered after 43.9 days. Two $S$. eboracensis $\times S$. vulgaris hybrids were recorded at Dalton Terrace in 1993, but no hybrids were found at the site in 1994.

Germination: Seeds of $S$. eboracensis germinated significantly earlier than seeds of $S$. vulgaris var. vulgaris at low temperatures $\left(5-15^{\circ} \mathrm{C}\right)$, while at $20^{\circ} \mathrm{C}$ there was no difference, and at $25^{\circ} \mathrm{C}$ the reverse was true (Figure 2). Seeds of $S$. eboracensis showed a similar pattern of germination to those of $S$. squalidus between 10 and $20^{\circ} \mathrm{C}$, but at $5^{\circ} \mathrm{C}$ were earlier to germinate and at $25^{\circ} \mathrm{C}$ were later to germinate.

Seedling establishment: Based on observations made along eight linear transects at Dalton Terrace in late 1994 and during 1995, it was evident that many more S. vulgaris than $S$. eboracensis seedlings were present at the site in November 1994, having germinated after the site had been cleared of plants in September 1994. However, by February 1995, this difference was much reduced (Figure 3a); indeed, only $48.8 \%$ of S. vulgaris seedlings successfully over-wintered compared to $79.2 \%$ for S. eboracensis. The number of individuals of both taxa present at the site continued to decline until July 1995, with very few new seedlings becoming established after winter. The ability of $S$. vulgaris to over-winter appeared to be correlated with the number of leaves it produced before winter. Those S. vulgaris plants that successfully over-wintered (ie were still alive in February) had significantly more leaves in November 1994 ( $t$-test, $P<0.001$; mean number leaves $=7.53, n=40$ ) relative to plants that died (mean number of leaves $=5.94, n=49$ ). This was not the case for S. eboracensis individuals (mean number of leaves on plants that survived winter $=6.86$, $n=18$; mean number of leaves on plants that died during winter $=6.94, n=7$ ). It was also evident from the number of capitula recorded per plant in March and July 1995 that $S$. vulgaris again flowered earlier than S. eboracensis (Figure 3b).

Conspecific clumping: The spatial distribution of adult plants of $S$. vulgaris and $S$. eboracensis at the Dalton Terrace site during 1994 showed significant clumping of conspecifics (Figure 4a, the observed Moran's Index of autocorrelation exceeds the upper $95 \%$ confidence limit). Clumps tended to be approximately 2-4 m across. Significant spatial autocorrelation was also found in the distribution of juveniles of the two species along the seedling establishment transects at the same site during 


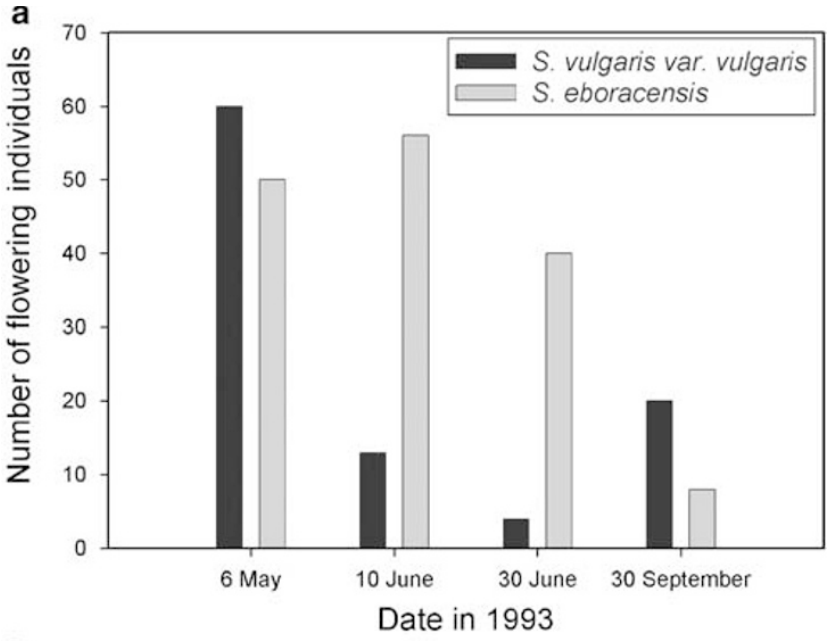

b
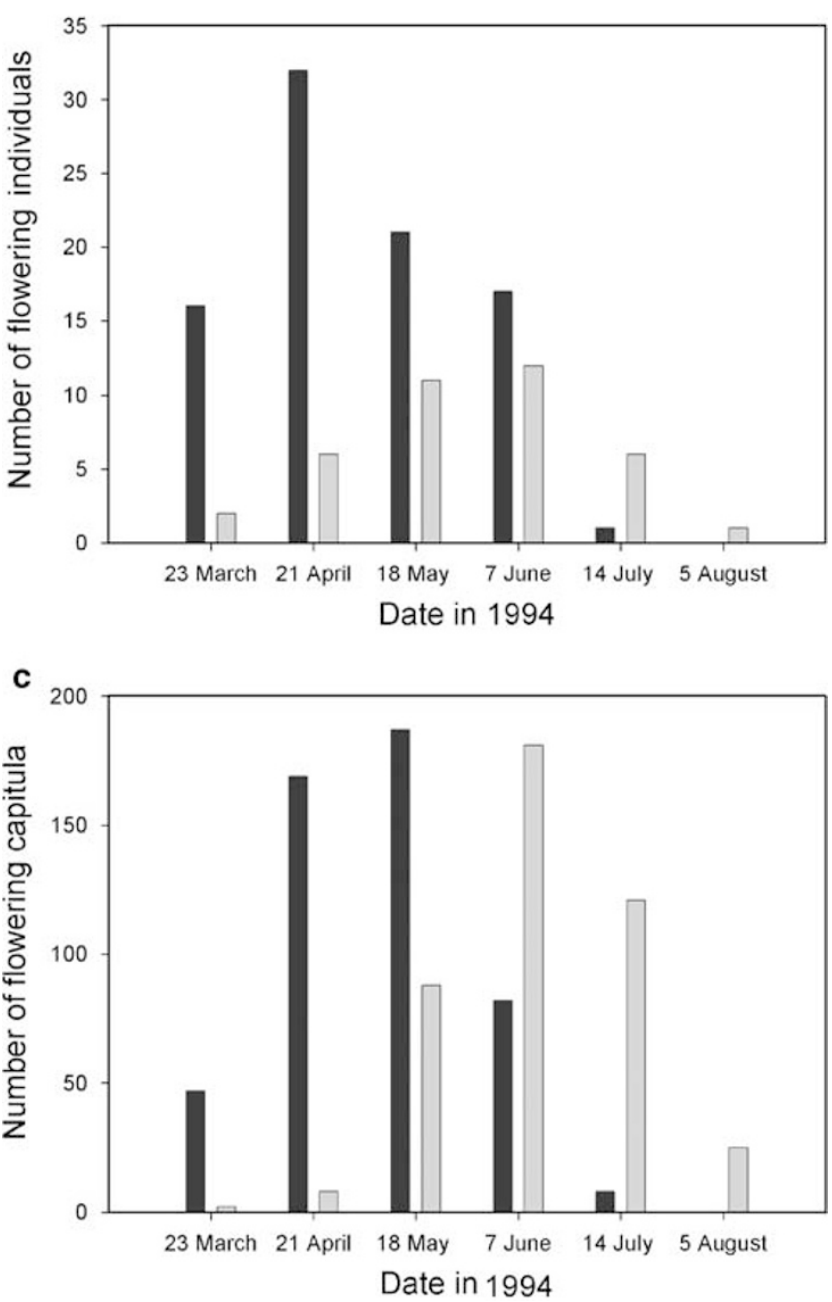

Figure 1 Number of individuals of each taxon flowering on a specified date at Dalton Terrace during (a) 1993 and (b) 1994. (c) Total number of flowering capitula produced by all plants of each taxa on a specified date at Dalton Terrace during 1994.

1994/1995. Although these eight transects were only $1 \mathrm{~m}$ long, almost all distance classes up to $1 \mathrm{~m}$ exhibit a significant effect of conspecific juvenile clumping (Figure 4b).
Hybrid formation in the wild and under experimental conditions of open-pollination

In the wild: In 1993, the frequency of the radiate allele (Tr) in the population of flowering plants at Dalton Terrace increased markedly from early May to late June (0.389-0. 909, Table 2). This reflected the later flowering time of $S$. eboracensis. The high values recorded for Wright's fixation index $(>0.95)$ indicate that levels of heterozygosity at the ray floret locus, and therefore hybridisation between $S$. eboracensis and S. vulgaris, were low. Progeny tests showed that the rate of hybrid formation by maternal plants was extremely low for $S$. eboracensis $\left(t_{(\operatorname{TrTr})}=0-0.0146\right)$ and was zero for $S$. vulgaris var. vulgaris. In 1994, progeny tests indicated that no hybrids were produced at Dalton Terrace.

Experimental conditions: Differences between the three different types of unit employed in the experiment explained the highest proportion of variation in the GLM of frequency of hybrid formation and was highly significant $(P<0.001$, Table 3$)$. Plot size (in terms of number of units per plot) and sampling date did not significantly influence levels of hybrid formation and there was no significant interaction between variables. For data pooled over different sampling dates (Table 4), the mean frequency of hybrid formation was highest for units in which $S$. eboracensis was surrounded by S. vulgaris var. vulgaris $(18.3 \%)$, and much lower in units with the reciprocal planting design (1.5\%). Only one triploid $F_{1}$ hybrid was raised from seed collected from units in which $S$. eboracensis was surrounded by S. squalidus plants yielding a mean frequency of hybrid formation equal to $0.1 \%$.

\section{Discussion}

It is clear from the low levels of interspecific hybridisation recorded in the wild and also under experimental conditions that the new hybrid species $S$. eboracensis is reproductively isolated from its parents, $S$. vulgaris and S. squalidus. In part, this is due to a strong prezygotic isolating barrier between $S$. eboracensis and $S$. vulgaris largely due to the predominant selfing of both species. Each species is self-compatible and sets high levels of seed when selfed (S. eboracensis - 78.8\%; S. vulgaris $82.4 \%$, Table 1). In addition, $S$. eboracensis is strongly isolated from $S$. squalidus by a postzygotic barrier due to a difference in ploidy, and less strongly from $S$. vulgaris by reductions in seed and pollen fertility. S. eboracensis was also found to exhibit greater winter survival of seedlings relative to $S$. vulgaris, indicating that these two species are ecologically differentiated to some extent and therefore likely to fill different ecological niches.

Fitness of hybrids and frequency of hybridisation between $S$. eboracensis and its parents $S$. squalidus and

\section{S. vulgaris}

As expected, a difference in ploidy between $S$. eboracensis $(2 n=40)$ and $S$. squalidus $(2 n=20)$ creates a very strong postzygotic breeding barrier between these two species. First-generation hybrids are triploid and highly sterile (mean seed set equals $0.63 \%$ ). On average, two trivalents, and from four to eight univalents were produced in meiotic cells of one hybrid examined, demonstrating a 

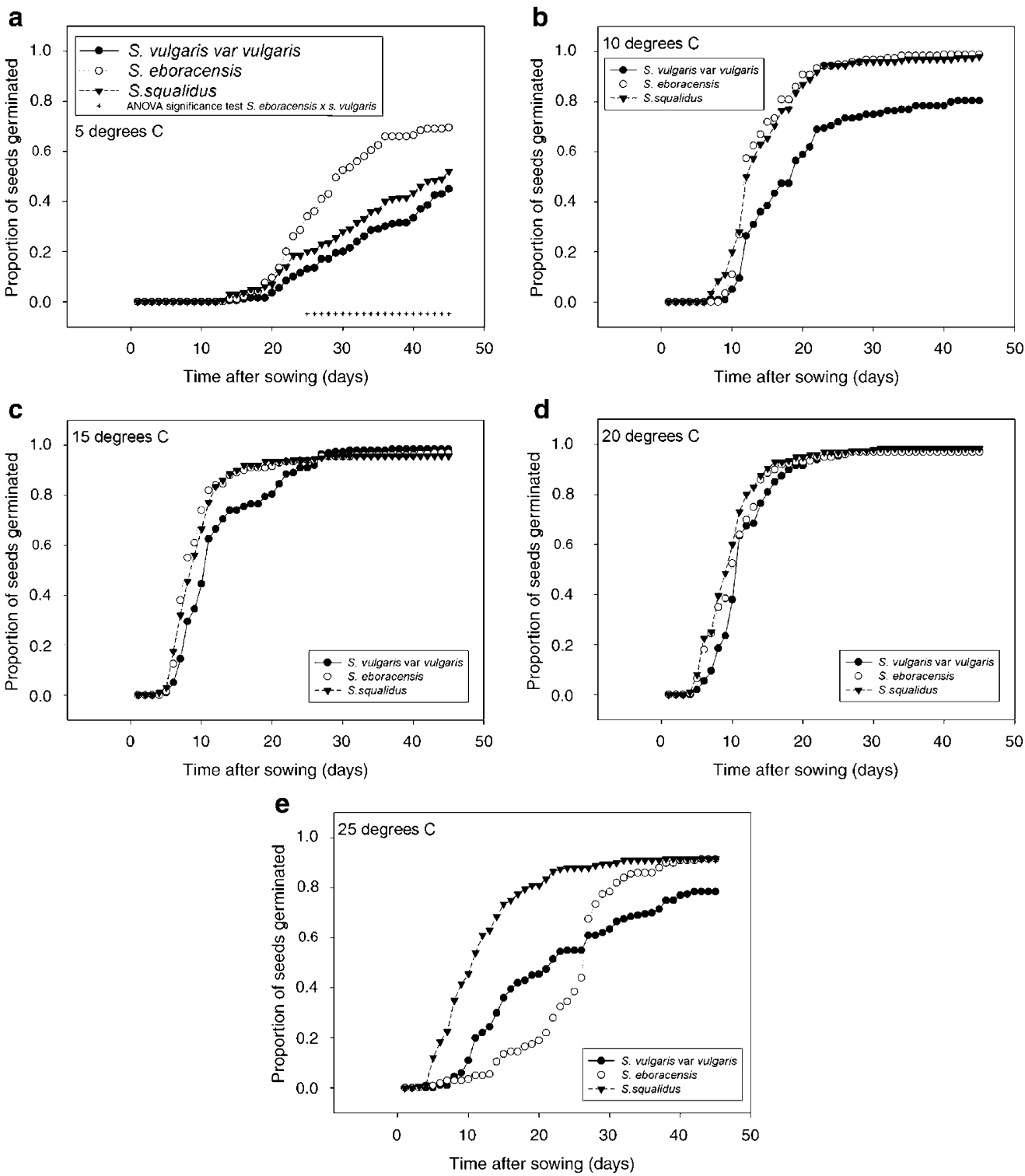

Figure 2 Cumulative proportion of seeds germinated over time at $\left(\right.$ a) $5^{\circ} \mathrm{C}$; (b) $10^{\circ} \mathrm{C}$; (c) $15^{\circ} \mathrm{C}$; (d) $20^{\circ} \mathrm{C}$; (e) $25^{\circ} \mathrm{C}$. Proportion of seeds germinated on each day were arcsine transformed and subjected to ANOVA, crosses indicate that there was a significant difference $(P<0.05)$ in the proportion of seeds germinated between S. vulgaris var. vulgaris and S. eboracensis.

high level of meiotic irregularity (Lowe, 1996). Later $\left(\mathrm{F}_{2}\right.$ and $\left.\mathrm{F}_{3}\right)$ and backcross $\left(\mathrm{B}_{1}\right.$ and $\left.\mathrm{B}_{1.2}\right)$ generations of this cross exhibited a wide range of fertilities, but in general fertility was higher than the $F_{1}$ generation indicating that a resumption in fertility, probably through genome stabilisation, may be possible for such products.

Hybridisation between S. eboracensis and S. squalidus is a rare event. No hybrids between these two species were recorded in the field, and the level of hybridisation was estimated to be only $0.1 \%$ when S. eboracensis plants were surrounded by S. squalidus on an experimental plot in the Botanic Gardens at St Andrews.

$F_{1}$ progeny of crosses between $S$. eboracensis and $S$. vulgaris exhibited significantly reduced mean seed set $(63.8 \%)$ compared to S. vulgaris $(82.4 \%)$ and significantly reduced pollen fertility $(97 \%)$ compared to $S$. eboracensis (99.6\%). Rather than recovering fertility, second-generation products of this cross exhibited a further reduction in mean seed set $(58.8 \%)$ compared to the parents (78.5 and $82.4 \%$, respectively, $P<0.001)$, although a wide range of seed fertilities were observed in the $\mathrm{F}_{2}$. For one $\mathrm{F}_{2}$ plant whose meiosis was examined, two univalents were observed indicating a lack of homology between one pair of chromosomes (Lowe, 1996). Backcross progeny demonstrated a recovery in seed fertility (66.1 and $67.2 \%$, respectively, for $B_{1}$ crosses to $S$. eboracensis and $S$. vulgaris, respectively), compared to $F_{1}(63.8 \%)$ and $F_{2}(58.8 \%)$ generations. The observed fluctuation in fertilities, particularly the wide range of variation observed in later generation products, is consistent with a genome stabilisation process. However, these results indicate that $S$. eboracensis must contain a substantial portion of the S. squalidus genome, or major structural rearrangement of the $S$. vulgaris genome, to 
392

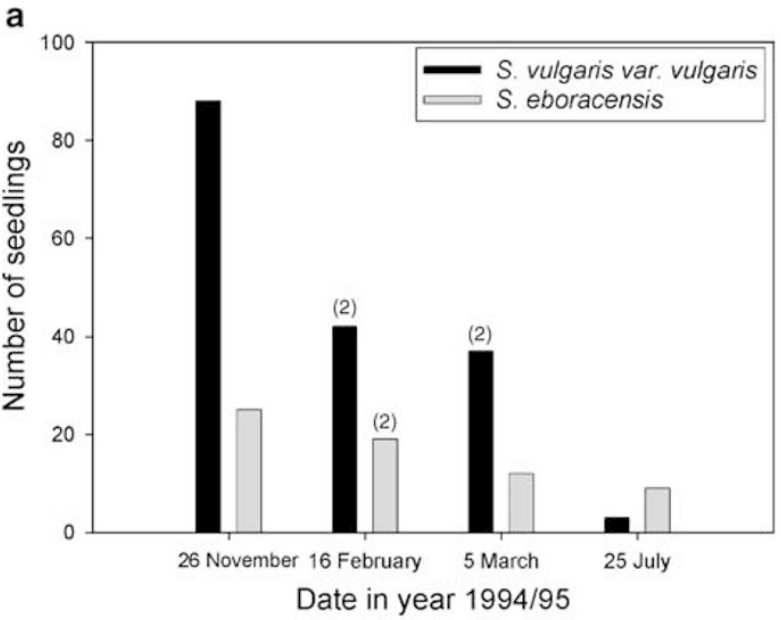

b

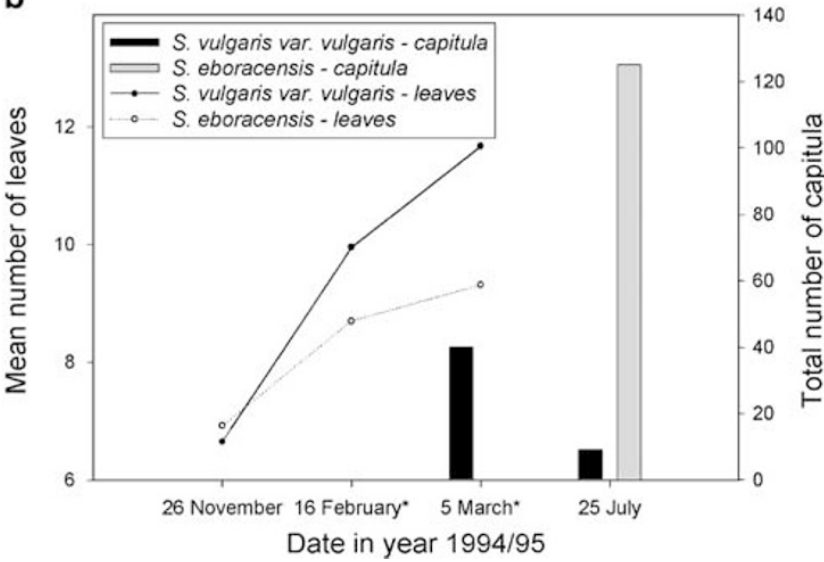

Figure 3 (a) Total number of seedlings of each taxon recorded on specific dates over the winter season 1994/95 at Dalton Terrace. The number of newly established seedlings is indicated in parentheses above bars. (b) Mean number of leaves per plant and total number of flowering capitula produced by all plants of each taxon between November 1994 and July 1995. Asterisks by date indicate significant difference $(P<0.05)$ in the mean number of leaves per plant between taxa.

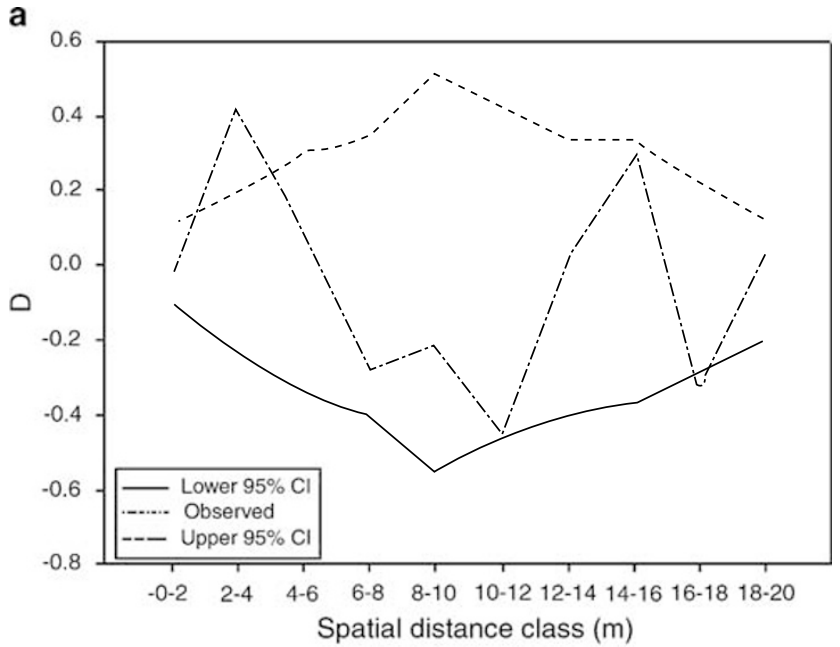

b

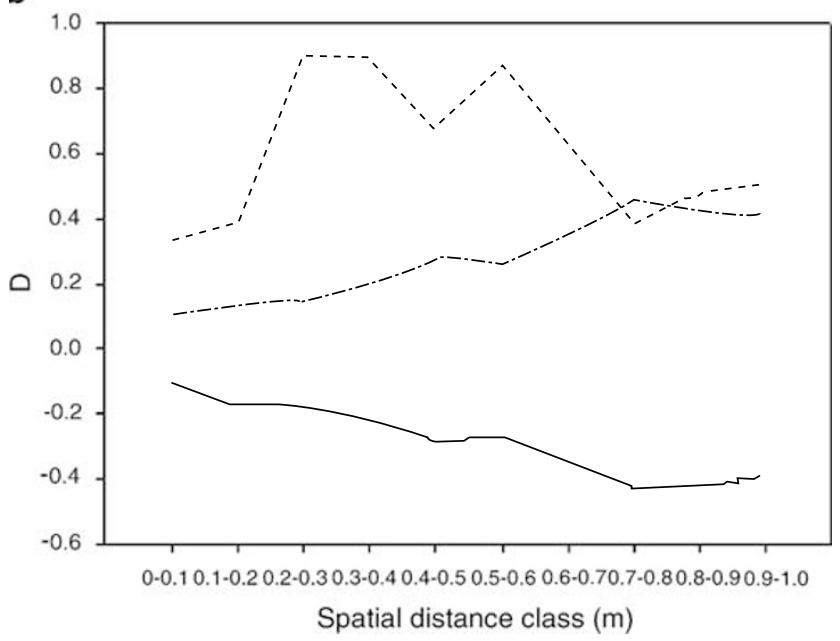

Figure 4 Test of spatial clustering of S. vulgaris and S. eboracensis plants at Dalton Terrace field site. Observed Moran's Index and 95\% confidence intervals plotted against spatial distance class for (a) flowering plant data from 1994 and (b) for seedling establishment plots from 1994/95.

Table 2 Number of flowering plants of each taxon and their hybrid at Dalton Terrace in 1993.

\begin{tabular}{|c|c|c|c|c|}
\hline Date & 6.5 .1993 & 10.6.1993 & 30.6 .1993 & 30.9 .1993 \\
\hline \multicolumn{5}{|l|}{ Flowering plants } \\
\hline S. eboracensis & 36 & 56 & 40 & 8 \\
\hline S. vulgaris var. vulgaris & 57 & 13 & 4 & 20 \\
\hline Hybrid & 2 & 1 & 0 & 0 \\
\hline S. eboracensis $(\operatorname{Tr} \operatorname{Tr})$ & 0.379 & 0.800 & 0.909 & 0.286 \\
\hline S. vulgaris $(T n T n)$ & 0.600 & 0.186 & 0.091 & 0.714 \\
\hline Hybrid $(\operatorname{Tr} T n)$ & 0.021 & 0.014 & 0 & 0 \\
\hline $\operatorname{Tr}$ & $0.389(0.239)$ & $0.807(0.535)$ & $0.909(0.406)$ & $0.286(0.007)$ \\
\hline$F$ & $0.956(0.138)$ & $0.954(0.080)$ & 1.000 & 1.000 \\
\hline \multicolumn{5}{|c|}{ Hybrid and total progeny scored } \\
\hline S. eboracensis & $2 / 223(36)$ & $1 / 475(50)$ & $0 / 268(34)$ & - \\
\hline S. vulgaris var. vulgaris & $0 / 396(57)$ & $0 / 127(9)$ & $0 / 19(3)$ & - \\
\hline$t_{(\operatorname{Tr} T r)}$ & $0.0146(0.009)$ & $0.0109(0.012)$ & 0 & - \\
\hline$t_{(\operatorname{TnTn})}$ & 0 & 0 & 0 & - \\
\hline
\end{tabular}

Genotype frequencies at the ray floret locus ( $\operatorname{Tr} T r$ - radiate, S. eboracensis; $\operatorname{Tr} T n$ - short rayed, hybrid; $\operatorname{Tn} \operatorname{Tn}$ - nonradiate, S. vulgaris), Wright's Fixation Index $(F)$, and the frequency of the radiate allele $(T r)$ at the site. Number of hybrids over total progeny scored (with number of maternal plants shown in parentheses) are also presented, plus the frequency of hybrid formation $t$ by maternal plants. Standard deviations are given in parentheses for $F, T r$ and $t_{(T r, T r}$ 
Table 3 Results of a GLM analysis on the frequency of hybrids produced by central plants in three different types of unit (S. eboracensis surrounded by S. vulgaris; S. eboracensis surrounded by S. squalidus, and S. vulgaris surrounded by $S$. eboracensis plants)

\begin{tabular}{|c|c|c|c|c|c|c|}
\hline Source & $D F$ & Seq SS & Adj SS & Adj $M S$ & $\mathrm{~F}$ & $\mathrm{P}$ \\
\hline Unit type (ut) & 2 & 1.10258 & 1.10258 & 0.55129 & 43.35 & 0.000 \\
\hline Plot size (ps) & 2 & 0.04250 & 0.04250 & 0.02125 & 1.67 & 0.193 \\
\hline Sampling date (d) & 5 & 0.09612 & 0.09612 & 0.01922 & 1.51 & 0.192 \\
\hline ut $\times$ ps & 4 & 0.04503 & 0.04503 & 0.01126 & 0.89 & 0.476 \\
\hline ut $\times d$ & 10 & 0.22292 & 0.22292 & 0.02229 & 1.75 & 0.078 \\
\hline $\mathrm{ps} \times \mathrm{d}$ & 10 & 0.03358 & 0.03358 & 0.00336 & 0.26 & 0.988 \\
\hline $\mathrm{ut} \times \mathrm{ps} \times \mathrm{d}$ & 20 & 0.07815 & 0.07815 & 0.00391 & 0.31 & 0.998 \\
\hline Error & 108 & 1.37355 & 1.37355 & 0.01272 & & \\
\hline Total & 161 & 2.99443 & & & & \\
\hline
\end{tabular}

Table 4 Percentage of hybrids produced for unit types in plots of different size after pooling data over sampling dates

\begin{tabular}{lccc}
\hline $\begin{array}{l}\text { Unit type } \\
\text { Central plant } \\
\text { Surround plants }\end{array}$ & $\begin{array}{c}\text { S. eboracensis } \\
\text { S. squalidus }\end{array}$ & $\begin{array}{c}\text { S. eboracensis } \\
\text { S. vulgaris var. vulgaris }\end{array}$ & $\begin{array}{c}\text { S. vulgaris var. vulgaris } \\
\text { S. eboracensis }\end{array}$ \\
\hline $\begin{array}{l}\text { No. progeny tested } \\
\text { Mean \% hybrids produced }\end{array}$ & 714 & 733 \\
$\begin{array}{l}\text { Small (single-unit plots) } \\
\text { Medium (two-unit plots) } \\
\text { Large (four-unit plots) } \\
\text { Mean }\end{array}$ & 0.3 & 13.6 & 762 \\
\hline
\end{tabular}

Means for unit type (over plots of different size) are significantly different $(P \leqslant 0.05)$ if they do not share the same superscript. Standard deviations are shown in parentheses.

cause significant fertility consequences when backcrossed to the parent with which it shares ploidy and much morphological similarity.

Hybridisation between $S$. eboracensis and S. vulgaris also occurs rarely in the wild. Two mature hybrids between these species were recorded at the Dalton Terrace site in 1993, and none was found there in 1994. Progeny tests of $S$. eboracensis offspring produced at this site yielded estimates of intertaxon crossing of $1.46 \%$, $1.09 \%$ and zero, respectively, on three different sampling dates during the main flowering period in May and June 1993. However, no hybrids were recorded among seeds sampled from $S$. vulgaris on the same dates. In addition, no hybrids were present among 997 S. eboracensis and S. vulgaris offspring produced at the site in 1994.

Rates of hybridisation will depend to some extent on the spatial arrangement of the species at a given site. Thus, when $S$. eboracensis was surrounded by plants of $S$. vulgaris on the experimental plot (conditions that would promote gene flow between the species), the frequency of hybrids among its offspring rose to $18.3 \%$. In contrast, the rate of hybridisation fell to $1.4 \%$ when $S$. vulgaris was surrounded by $S$. eboracensis. This difference may be partly or wholly explained by the fact that $S$. eboracensis produces radiate capitula comprised of a mix of ray and disc florets. Ray florets are male sterile and open first within a capitulum to promote outcrossing (Marshall and Abbott, 1984). In contrast, S. vulgaris produces nonradiate capitula composed entirely of hermaphrodite disc florets that are known to show very low levels of outcrossing (Marshall and Abbott, 1984). There may also be a pollinator-mediated effect contributing to differences in rates of hybrid formation. $S$. eboracensis plants are much more conspicuous to the eye than $S$. vulgaris due to the possession of ray florets, and also produce more stigmatic papillae, which can promote the capture of incoming pollen (Richards, 1986). In addition, $S$. eboracensis produces more pollen grains per floret than S. vulgaris (Lowe, 1996), and pollen is a major food source of hoverflies, the most common pollinator of ragwort and groundsel (Gilbert, 1986). Abbott and Irwin (1988) showed that nonradiate capitula of $S$. vulgaris are less attractive to pollinators relative to radiate capitula. Thus, pollinator transition flights and associated pollen flow from $S$. vulgaris to $S$. eboracensis may be more common than transition flights and pollen flow in the reverse direction. This could boost the maternal intertaxon crossing rate of $S$. eboracensis relative to that of $S$. vulgaris.

One potential complicating factor of such a crossing bias is a cytoplasmic/maternal interaction. Previous work on cpDNA variation and resynthesis studies indicate that $S$. vulgaris most probably acted as the maternal parent during the formation of S. eboracensis (Abbott and Lowe, 1996; Lowe and Abbott, 2000). Based upon these results, both taxa share similar if not identical cytoplasmic genomes and such a bias may be ruled out, although further work on this issue may be advisable.

\section{Ecological differentiation (including phenology) and taxon distribution}

At Dalton Terrace, S. vulgaris plants flowered mainly from April to June, whereas S. eboracensis plants flowered mainly between May and July in both 1993 and 1994. S. eboracensis was also observed to flower later than S. vulgaris in 1995. S. vulgaris seeds germinated more rapidly than those of $S$. eboracensis at high temperatures, and field observations showed that $S$. vulgaris seedlings developed more quickly in early spring relative to those 
of S. eboracensis. Both observations would promote earlier flowering in S. vulgaris individuals produced from seeds that were shed in late summer and which germinated during early autumn. Although phenological separation is an important prezygotic isolating mechanism between related species (Levin, 1978, 2000), it is probably only a contributing mechanism in the case of $S$. eboracensis and $S$. vulgaris as low levels of intertaxon crossing were recorded during periods when both species were flowering synchronously (May and June).

Another factor that could significantly reduce the level of intertaxon crossing in the wild is conspecific clumping of $S$. vulgaris and $S$. eboracensis plants, which was recorded at the Dalton Terrace site. Given the expected greater attractiveness of $S$. eboracensis to pollinators, pollinator visitation is likely to be more prevalent within and between clumps of this species, rather than between clumps of the two species.

S. eboracensis co-occurs with $S$. vulgaris in the wild, and might be expected therefore to have a very similar ecology. However, seedling survival over winter was proportionally much lower for $S$. vulgaris than S. eboracensis. There was a significant positive correlation between the number of leaves present before the winter period and the likelihood of winter survival for $S$. vulgaris (ie larger plants are more likely to survive), but not for $S$. eboracensis. Slug tracks and damage to plants were noted during all field visits. The slug, Deroceras reticulatum, is known to preferentially feed on groundsel plants, causing mortality of smaller individuals. A study of mollusc grazing by Warren (1987) found that seedling mortality was significantly higher for S. vulgaris than for radiate groundsel plants from York, and the latter in turn were preferentially grazed compared to $S$. squalidus. These observations indicate niche separation between the taxa.

\section{Expectations of reproductive isolating mechanisms from modelling studies}

McCarthy et al (1995) have shown that homoploid hybrid speciation is most likely to occur if the hybrid is predominantly autogamous. More recently, Buerkle et al (2000) showed that in cases where a hybrid reproduces by outcrossing, ecological and spatial isolation were crucial to the establishment of a new homoploid hybrid species. Husband and Schemske (2000) have further demonstrated that the establishment of an autopolyploid in sympatry with its diploid parent will be greatly enhanced by assortative mating caused by asynchronous flowering and pollinator preference. In addition, several studies (McCarthy et al, 1995; Husband and Schemske, 2000) have identified a clumped distribution as an important factor to reduce intertype pollinations.

In the current study, crosses between S. eboracensis and both parent taxa produce progeny of reduced fertility. In addition, S. eboracensis appears to be predominantly autogamous and the level of interbreeding with parent taxa is further reduced in the field by phenological differences, pollinator preference and a clumped distribution. There are probably also some ecological tolerance differences between $S$. eboracensis and its parents, which could further reduce intertaxon crossing and competition effects.
It is clear, therefore, that a combination of several characters promotes pre- and post zygotic reproductive isolation between $S$. eboracensis and its parents, and will have helped the establishment of this new species during the period following its origin (approximately 30-50 years ago), that is when its numbers remained low (Lowe and Abbott, 2003). Thus the new species will have been subject to a much reduced level of minority type disadvantage during its establishment phase. It is likely that the suite of characters causing reproductive isolation was present in the neospecies when it first originated. However, the relative roles of selection and stochastic effects in the formation of this suite of characters in the new hybrid remain to be assessed.

\section{Acknowledgements}

We are grateful to David Forbes for his assistance in the greenhouse, to Ron Smith for advice with statistical methods and to Stephen Harris for constructive comments on an early version of the manuscript. The research was conducted while AJL held a research studentship from the NERC.

\section{References}

Abbott RJ (1992). Plant invasions, interspecific hybridization and the evolution of new plant taxa. TREE 7: 401-405.

Abbott RJ, Forbes DG (1993). Outcrossing rate and selfincompatibility in the colonizing species Senecio squalidus L. Heredity 71: 155-159.

Abbott RJ, Irwin JA (1988). Pollinator movements and the polymorphism for outcrossing rate at the ray floret locus in Groundsel, Senecio vulgaris L. Heredity 60: 295-298.

Abbott RJ, Lowe AJ (1996). A review of hybridization and evolution in British Senecio. In: Hind DJN, Beentje HJ (eds) Compositae: Systematics. Proceedings of the International Compositae Conference, Kew 1994. Royal Botanic Gardens, Kew: UK, 1 pp 679-689.

Arnold ML (1997). Natural Hybridization and Evolution. Oxford Series in Ecology and Evolution. Oxford University Press: Oxford.

Buerkle CA, Morris RJ, Asmussen MA, Rieseberg LH (2000). The likelihood of homoploid hybrid speciation. Heredity 84: 441-451.

Degen B, Petit R, Kremer A (2001). SGS—spatial genetic software: a computer program for analysis of spatial genetic and phenotypic structures of individuals and populations. J Hered 92: 447-449.

Felber F (1991). Establishment of a tetraploid cytotype in a diploid population: effect of relative fitness of the cytotypes. J Evol Biol 4: 195-207.

Gilbert FS (1986). Hoverflies. Naturalist's Handbooks 5. Cambridge Press: Cambridge.

Grant V (1981). Plant Speciation. Columbia University Press: NY.

Hiscock SJ (2000a). Genetic control of self-incompatibility in Senecio squalidus L. (Asteraceae): a successful colonizing species. Heredity 85: 10-19.

Hiscock SJ (2000b). Self-incompatibility in Senecio squalidus L. (Asteraceae). Ann Bot 85(Suppl A): 181-190.

Horrill C (1989). Demographic Genetics of the Polymorphism for Capitulum Type and Associated Outcrossing Rate in S. vulgaris L. PhD Thesis. University of St Andrews: Scotland.

Husband BC (2000). Constraints on polyploid evolution: a test of the minority cytotype exclusion principle. Proc Roy Soc London, Ser B 267: 217-223. 
Husband BC, Schemske DW (2000). Ecological mechanisms of reproductive isolation between diploid and tetraploid Chamerion angustifolim. J Ecol 88: 689-701.

Irwin JA, Abbott RJ (1992). Morphometric and isozyme evidence for the hybrid origin of a new tetraploid radiate goundsel in York, England. Heredity 69: 431-439.

Levin DA (1975). Minority cytotype exclusion in local plant populations. Taxon 24: 35-43.

Levin DA (1978). The origin of isolating mechanisms in flowering plants. Evol Biol 11: 185-317.

Levin DA (2000). The Origin, Expansion, and Demise of Plant Species. Oxford Series in Ecology and Evolution. Oxford University Press Inc: USA.

Lowe AJ (1996). The Origin and Maintenance of a New Tetraploid Senecio Hybrid in York. PhD Thesis. University of St Andrews: Scotland.

Lowe AJ, Abbott RJ (2000). Routes of origin of two recently evolved hybrid taxa: Senecio vulgaris var. hibernicus and York radiate groundsel (Asteraceae). Am J Bot 87: 1159-1167.

Lowe AJ, Abbott RJ (2003). A new British species, Senecio eboracensis (Asteraceae), another hybrid derivative of S. vulgaris L. and S. squalidus L. Watsonia 24: 375-388.

Marshall DF, Abbott RJ (1982). Polymorphism for outcrossing frequency at the ray floret locus in Senecio vulgaris L. I Evidence. Heredity 48: 227-235.

Marshall DF, Abbott RJ (1984). Polymorphism for outcrossing frequency at the ray floret locus in Senecio vulgaris L. III Causes. Heredity 53: 145-149.

McCarthy EM, Asmussen MA, Anderson WW (1995). A theoretical assessment of recombinational speciation. Heredity 74: 502-509.

Richards AJ (1986). Plant Breeding Systems. George Allen and Unwin: London.

Rieseberg LH (1997). Hybrid origins of plant species. Ann Rev Ecol Syst 28: 359-389.
Rieseberg LH, Carney SE (1998). Plant hybridization, Tansley review no. 102. New Phytol 140: 599-624.

Rieseberg LH, Fossen CV, Desrochers AM (1995). Hybrid speciation accompanied by genomic reorganization in wild sunflowers. Nature 375: 313-316.

Rieseberg LH, Sinervo B, Linder CR, Ungerer MC, Arias DM (1996). Role of gene interactions in hybrid speciation: evidence from ancient and experimental hybrids. Science 272: 741-745.

Schwarzbach AE, Donovan LA, Rieseberg LH (2001). Transgressive character expression in a hybrid sunflower species. Am J Bot 88: 270-277.

Soltis DE, Soltis PS (1993). Molecular data and the dynamic nature of polyploidy. Crit Rev Plant Sci 12: 243-273.

Soltis DE, Soltis PS (1999). Polyploidy: recurrent formation and genome evolution. TREE 14: 348-352.

Straw RM (1955). Hybridization, homogamy, and sympatric speciation. Evolution 9: 441-444.

Straw RM (1956). Floral isolation in Penstemon. Am Nat 90: 47-53.

Warren JM (1987). The Origin and Maintenance of the Capitulum Polymorphism in Senecio vulgaris L. (groundsel) DPhil Thesis. University of York: England.

Welch ME, Rieseberg LH (2002). Habitat divergence between a homoploid hybrid sunflower species, Helianthus paradoxus (Asteraceae), and its progenitors. Am J Bot 89: 472-478.

Winge Ö (1917). The chromosomes: their numbers and general importance. Comptes Rendus Travaux du Laboratoire Carlsberg 13: $131-275$.

Wolfe AD, Xiang Q-Y, Kephart SR (1998a). Diploid hybrid speciation in Penstemon (Scrophulariaceae). Proc Natl Acad Sci USA 95: 5112-5115.

Wolfe AD, Xiang Q-Y, Kephart SR (1998b). Assessing hybridization in natural populations of Penstemon (Scrophulariaceae) using hypervariable intersimple sequence repeat (ISSR) bands. Mol Ecol 7: 1107-1125. 